\title{
Simultaneous Letrozole and Clomiphene Citrate versus Letrozole Alone in Clomiphene Citrate Resistant Polycystic Ovary Syndrome: A Randomised Controlled Trial
}

\author{
Mohamed A. Ibrahem \\ Obstetrics and Gynaecology Department, Faculty of Medicine, Zagazig University, Zagazig, Egypt \\ Email: dr_mohamed_abdelmoniem@yahoo.com
}

How to cite this paper: Ibrahem, M.A. (2019) Simultaneous Letrozole and Clomiphene Citrate versus Letrozole Alone in Clomiphene Citrate Resistant Polycystic Ovary Syndrome: A Randomised Controlled Trial. Open Journal of Obstetrics and Gynecolo$g y$, 9, 1532-1540.

https://doi.org/10.4236/ojog.2019.911149

Received: October 30, 2019

Accepted: November 24, 2019

Published: November 27, 2019

Copyright $\odot 2019$ by author(s) and Scientific Research Publishing Inc. This work is licensed under the Creative Commons Attribution International License (CC BY 4.0). http://creativecommons.org/licenses/by/4.0/

\section{Open Access}

\begin{abstract}
Background: Polycystic ovary syndrome (PCOS) is a common cause of anovulatory infertility. The therapeutic strategies for clomiphene citrate (CC)resistant patients include the addition of corticosteroids, extended duration of clomiphene, gonadotrophin therapy, laparoscopic ovarian drilling, in vitro fertilization or the use of aromatase inhibitors recently. Letrozole decreases estrogen levels in the body, so it releases the hypothalamus and/or pituitary gland from the negative feedback of estrogen. This increases levels of gonadotrophins, which stimulates follicular growth. Objectives: To evaluate the role of letrozole alone and simultaneous use of letrozole and clomiphene citrate (CC) for ovulation induction in patients with clomiphene citrate-resistant PCOS (CCR-PCOS). Patients and Methods: This open-label randomised controlled study was conducted in the Department of Obstetrics and Gynecology, Faculty of Medicine, Zagazig University, Egypt during the period from February 2018 to June 2019. The study included 60 CCR-PCOS patients who were randomly allocated by independent personnel into two arms: group A (letrozole alone) or B (letrozole + CC). In either group, monitoring the mean follicular diameter and endometrial thickness in the days 10,12, and 14 of the cycle by transvaginal ultrasound and Measurement of serum Progesterone $(\mathrm{ng} / \mathrm{ml}) 7$ days after the expected time of ovulation. Results: We investigated various clinical and sonographic factors that may predict the outcome of the method of induction of ovulation in CCR-PCOS with no significant affection for the results. There was a non-significant difference between the studied groups regarding ovulation and pregnancy per cycle or per patient. Conclusion: Letrozole alone or simultaneous use of letrozole and CC offers a good second-line option for induction of ovulation in CCR-PCOS patients.
\end{abstract}


However, the combination of CC and letrozole did not add any benefit over the use of letrozole alone regards ovulation rate, follicular volume, endometrial thickness, pregnancy rate and live birth rate.

\section{Keywords}

Ovulation Induction, Letrozole, Clomiphene Citrate,

Polycystic Ovary Syndrome

\section{Introduction}

Polycystic ovary syndrome (PCOS) is a common cause of infertility that affects $4 \%-8 \%$ of reproductive-age females [1]. Diagnosis of PCOS is very important for proper management. In literature, Rotterdam criteria are widely used for diagnosis and focus on polycystic ovarian morphology on ultrasound, a history of ovulatory disorders (oligo-anovulation), and clinical/biochemical signs of hyperandrogenism requiring two of three features after exclusion of other endocrinopathies [2].

Clomiphene citrate (CC) is still holding its place for ovulation induction being simple, safe, cheap and effective [3] [4]. However, clomiphene-resistance, i.e., failure to ovulate after receiving $150 \mathrm{mg} /$ day for at least three cycles for five days per cycle affects $15 \%$ - 40\% of patients with PCOS [5]. Factors involved in CC resistance include increased body mass index, Insulin resistance, and hyperandrogenemia; Also, a hereditary predisposition plays a role [6].

Gonadotrophin induced ovulation or laparoscopic ovarian drilling (LOD) usually used as a second-line management of patients with CC resistant [7]. However, they carry many drawbacks; gonadotrophinstherapy is expensive, requires appropriate monitoring and associated with significantly increased risk for ovarian hyperstimulation syndrome (OHSS) and multiple pregnancy [8]. While LOD needs general anesthesia and carries a risk of postoperative adhesions [9].

Many tissues including the ovary (in premenopausal women), fat, muscle, breast and liver contain aromatase enzyme which controls the final step in estrogen synthesis, It is responsible for aromatization of androstenedione and testosterone into estrone and estradiol, respectively. This process can be inhibited by administration of a third-generation aromatase inhibitor such as letrozole by $>99 \%[10]$.

Letrozole has become the first line drug for induction of ovulation in PCOS patients [11]. It decreases estrogen levels in the body, so it releases the hypothalamus and/or pituitary gland from the negative feedback of estrogen. This result in increased levels of endogenous follicle-stimulating hormone (FSH) and luteinizing hormone (LH), which stimulates follicular growth [12].

Several studies compared between letrozole and CC in PCOS, and few studies compared combination of letrozole and CC versus letrozole alone in PCOS [13] 
[14]. However no study compared between them in clomiphene-resistant PCOS (CCR-PCOS).

The aim of this prospective randomized study was to evaluate the role of letrozole alone and simultaneous use of letrozole and clomiphene citrate (CC) in induction of ovulation in patients with clomiphene-resistant PCOS (CCRPCOS).

\section{Patients and Methods}

This open-label randomised controlled study was conducted in the Department of Obstetrics and Gynecology, Faculty of Medicine, Zagazig University, Egypt during the period from February 2018 to June 2019. The study included 60 women with infertility secondary to PCOS according to ESHRE/ASRM (Rotterdam criteria) 2003 [15] and after exclusion of other endocrinopathies. Patients with at least two of the following; clinical and/or biochemical hyperandrogenism, oligo-ovulation or anovulation, polycystic ovaries by sonography (ovarian volume more than $10 \mathrm{ml}$ with multiple small cysts; more than 12 follicle each one 2 - $9 \mathrm{~mm}$ in diameter), with previously documented anovulation by transvaginal ultrasound follicular monitoring while taking clomiphene citrate in a dose of $150 \mathrm{mg} /$ day (clomiphene citrate resistant).

Other inclusion criteria were age between 18 to 35 years with Body Mass Index (BMI) not more than $35 \mathrm{~kg} / \mathrm{m}^{2}$, free of any medical disease and not receiving medications in the last 3 months apart from clomiphene citrate.

Patients with other causes of infertility, gross ovarian pathology diagnosed by ultrasound, previous tubal or ovarian surgery or LOD were excluded from the study.

The study proposal was approved by the Institutional Review Board of Faculty of Medicine, Zagazig University. Written informed consent was taken from all participants after the explanation of drugs used in the study with their side effects. Full history taking, general, abdominal and local examination, abdominal and transvaginal ultrasound and other investigations could be done to fulfill the inclusion and exclusion criteria.

Basal ultrasound imaging was performed on the second day of the cycle (CD2) to assess the mean follicular diameter and endometrial thickness.

Serum levels of LH, FSH, and free testosterone were measured in the early follicular phase $(\mathrm{CD} 2)$.

In order to detect a clinically meaningful $33 \%$ absolute difference in ovulation rate between treatment groups to achieve $80 \%$ statistical power, thirty patients were required for each group assuming a 50\% ovulation rate for letrozole group by the use of the Pearson chi-square test with a two-sided significance level of 0.05 .

The patients were randomly allocated in a ratio of 1:1 using online software (http://www.randomization.com) by independent personnel into study arms; group A (letrozole alone) or B (letrozole + CC). Once allocated, the treatment 
was revealed to both the investigator and the patient.

Initially, withdrawal bleeding was achieved (if the patient was amenorrhoic) using progesterone tablets for 10 days before stimulation cycles.

Group A: letrozole group, Stimulation using $5 \mathrm{mg}$ of letrozole oral tablets daily from day 2 of the cycle for 5 days and then followed up for ovulation and pregnancy if occurred and this repeated for up to the next 6 months.

Group B: letrozole + CC group, Patients received $100 \mathrm{mg}$ CC plus $5 \mathrm{mg}$ of letrozole daily starting on cycle day 2 for 5 days and then followed up for ovulation and pregnancy if occurred and this repeated for up to the next 6 months.

Actually, those who did not ovulate following 6 successive cycles of letrozole with or without CC at the same dose had been considered not responsive and were counseled for further lines of treatment.

The study compared different variables between both groups such as the effects of drugs on follicular growth and endometrial thickness through monitoring by transvaginal ultrasound for the mean follicular diameter and endometrial thickness in the days 10,12, and 14 of the cycle. HCG in a dose of 10.000 IU was given when one follicle reached at least $18 \mathrm{~mm}$. Patients then advised having intercourse 24 - 36 hours after hCG injection. Compared variables include ovulation rate through stigmata of ovulation on transvaginal ultrasound and by measuring serum progesterone level $(\mathrm{ng} / \mathrm{ml})$ one week after the expected time of ovulation.

Both groups are compared regarding biochemical pregnancy which was considered when serum B-hCG $\geq 50 \mathrm{mIU} / \mathrm{ml}$ in the absence of menstruation two weeks after the expected time of ovulation. Meanwhile, the sonographic evidence for intrauterine gestational sac at 6 weeks of gestation was considered criteria to define a clinical pregnancy. Lastly live birth rates were compared through follow up all pregnant participants till delivery.

\section{Statistical Analysis}

This study data are presented as mean \pm SD for continuous variables. The frequency and percentage were used for the categorical ones. Comparisons between quantitative variables were done using an independent sample T-test. For comparing the categorical data chi-squared test was performed. SPSS 17.0 (SPSS, Chicago, IL, USA) was used in the statistical analysis. Statistical significance was considered at $\mathrm{p}<0.05$.

\section{Results}

Both groups are comparable regarding socio-demographic and clinical characteristics with mean age $25.65 \pm 6.09$ years in group $A$, and $25.46 \pm 4.6$ years in group B. and period of infertility $3.57 \pm 1.14$ years in group A, and $3.93 \pm 1.63$ years in group B. Also baseline investigations were comparable and ovarian volume on baseline ultrasound with Antral follicle count (AFC) $16.43 \pm 3.8$ in Group A and $18.10 \pm 4.02$ in Group B. 
There were non-significant differences between the studied groups regarding; Age, Period of infertility, LH level, FSH level, LH/FSH ratio, testosterone level, Right and left ovarian volume and antral follicle count (AFC) $(p>0.05)$ (Table 1).

There was no significant difference between studied groups regarding follicular diameter in cycle day 10 (CD10), which became slightly higher in group B in cycle day $14(\mathrm{p}=0.049)$. As regard endometrial thickness; there was no significant difference between studied groups (Table 2).

Progesterone measured seven days after the expected time of ovulation was greater in women who received letrozole and CC than those who received letrozole alone $(14.92 \pm 8.09 \mathrm{ng} / \mathrm{ml}$ versus $8.03 \pm 6.64 \mathrm{ng} / \mathrm{ml}$ respectively $)(\mathrm{p}=$ $0.0004)$.

In the first cycle of treatment, there were non-significant differences between the studied groups regarding ultrasound stigmata of ovulation, biochemical and clinical pregnancy rates (Table 3 ).

Ovulation, pregnancy and live birth rates per total cycle of treatment were almost equal in studied groups (Table 4).

The number of patients who had ovulation in group A was 22; all of them except one occurred in the first 3 cycles of treatment while in group B 21 patients had ovulation during the first 3 cycles of treatment, and non-responded after that (Table 5).

Table 1. Patients' characteristics in the studied groups.

\begin{tabular}{cccc}
\hline & Letrozole & Letrozole + CC & p \\
\hline Age (years) & $25.65 \pm 6.09$ & $25.46 \pm 4.6$ & 0.87 \\
Period of infertility (years) & $3.57 \pm 1.14$ & $3.93 \pm 1.63$ & 0.35 \\
FSH (mIU/ml) & $5.43 \pm 1.68$ & $5.41 \pm 1.84$ & 0.96 \\
LH (mIU/ml) & $8.95 \pm 2.58$ & $8.34 \pm 2.41$ & 0.39 \\
LH/FSH ratio & $1.79 \pm 0.74$ & $1.73 \pm 0.76$ & 0.72 \\
Testosterone $\left(\mathrm{ng} / \mathrm{ml}^{2}\right.$ & $0.66 \pm .18$ & $0.59 \pm .22$ & 0.15 \\
BMI (kg/m $\left.{ }^{2}\right)$ & $28.23 \pm 3.06$ & $28.10 \pm 4.4$ & 0.87 \\
Right ovarian volume $\left(\mathrm{mm}^{3}\right)$ & $12.27 \pm 2.24$ & $12.8 \pm 3.36$ & 0.41 \\
Left ovarian volume $\left(\mathrm{mm}^{3}\right)$ & $12.18 \pm 1.96$ & $12.3 \pm 2.86$ & 0.85 \\
Antral follicle count $\left(\mathrm{AFC}^{3}\right)$ & $16.43 \pm 3.8$ & $18.10 \pm 4.02$ & 0.11 \\
\hline
\end{tabular}

Table 2. Patients' follow up cycles (folliculometry and endometrial thickness).

\begin{tabular}{cccc}
\hline & Letrozole & Letrozole + CC & p \\
\hline CD10 follicular size $(\mathrm{mm})$ & $10.62 \pm 2.01$ & $11.35 \pm 2.85$ & 0.29 \\
CD 14 follicular size $(\mathrm{mm})$ & $17.65 \pm 3.94$ & $19.47 \pm 2.63$ & $0.049^{*}$ \\
CD2 Endometrial thickness $(\mathrm{mm})$ & $4.94 \pm 1.88$ & $4.53 \pm 0.88$ & 0.13 \\
$\begin{array}{c}\text { Endometrial thickness }(\mathrm{mm}) \text { in } \\
\text { day of hCG injection }\end{array}$ & $9.09 \pm 2.64$ & $8.94 \pm 3.48$ & 0.85 \\
Progesterone CD21-23 $(\mathrm{ng} / \mathrm{ml})$ & $8.03 \pm 6.64$ & $14.92 \pm 8.09$ & $0.0004^{* *}$ \\
\hline
\end{tabular}


Table 3. Ultrasound stigmata of ovulation, biochemical and clinical pregnancy rates in $1^{\text {st }}$ cycle of treatment.

\begin{tabular}{cccc}
\hline & $\begin{array}{c}\text { Letrozole } \\
(\mathbf{N}=30)\end{array}$ & $\begin{array}{c}\text { Letrozole }+ \text { CC } \\
(\mathbf{N}=30)\end{array}$ & $\mathrm{p}$ \\
\hline Stigmata of ovulation & $19(63.3 \%)$ & $19(63.3 \%)$ & - \\
Biochemical pregnancy & $4(13.3 \%)$ & $6(20 \%)$ & 0.47 \\
Clinical pregnancy & $3(10.0 \%)$ & $2(6.7 \%)$ & 0.64 \\
\hline
\end{tabular}

Table 4. Ovulation, pregnancy and live birth rates per total cycles of treatment.

\begin{tabular}{cccc}
\hline & $\begin{array}{c}\text { Letrozole } \\
(\mathbf{N}=94)\end{array}$ & $\begin{array}{c}\text { Letrozole }+ \text { CC } \\
(\mathbf{N}=93)\end{array}$ & $\mathbf{p}$ \\
\hline Ovulation & $65(69.1 \%)$ & $65(69.8 \%)$ & 0.91 \\
Pregnancy & $12(12.8 \%)$ & $11(11.9 \%)$ & 0.84 \\
Live birth & $8(8.8 \%)$ & $7(7.5 \%)$ & 0.8 \\
\hline
\end{tabular}

Table 5. Number of cycles passed to achieve ovulation per each patient.

\begin{tabular}{cccc}
\hline & $\begin{array}{c}\text { Letrozole } \\
(\mathbf{n}=30)\end{array}$ & $\begin{array}{c}\text { Letrozole }+ \text { CC } \\
(\mathbf{n}=30)\end{array}$ & $\mathbf{p}$ \\
\hline$<3$ cycles & $21(70.0 \%)$ & $21(70.0 \%)$ & \\
$>3$ cycles & $1(3.3 \%)$ & $0(0 \%)$ & 0.58 \\
No ovulation & $8(26.7 \%)$ & $9(30.0 \%)$ & \\
\hline
\end{tabular}

\section{Discussion}

Ovulation induction in women with PCOS who presented with CC resistant remains a major challenge in gynecologic endocrinology. Gonadotrophin therapy or ovarian drilling is the usual second-line treatment in CC resistant. However, they carry many drawbacks; letrozole can be used instead with lower cost and lower risk of complications. In addition both CC and letrozole have a different mechanism of actions this makes letrozole a promising agent for treatment in those patients either alone or in combination with CC that may provide complementary effects.

Although several studies compared the effect of letrozole and CC in PCOS, And few studies compared combination of letrozole and CC versus letrozole alone in PCOS [13] [14]. However no study compared between them in clomiphene-resistant PCOS (CCR-PCOS).

In this clinical study, we compared the effect of letrozole alone versus letrozole plus CC in 60 patients with CCR-PCOS (30 in each group). Both groups were comparable regarding; Age, Period of infertility, LH level, FSH level, LH/FSH ratio, testosterone level, Right and left ovarian volume and antral follicle count (AFC) to minimize any possible bias in patients' selection.

Although CC has antiestogenic effects on endometrial thickness, when combined with letrozole in this study there was no significant difference in endometrial thickness at time of ovulation when compared with letrozole alone. 
There was a marked improvement in ovulation rate in patients with CCRPCOS after administration of either letrozole alone or letrozole + CC; the ovulation rate in the first cycle of treatment was matched in both groups (19 patient in each; 63.3\%). Most of the patients had ovulation during the first 3 cycles of treatment in both groups.

The overall ovulation rate per total cycles of treatment was $69.1 \%$ in group A and $69.8 \%$ in group B. Pregnancy rate and live birth rate per total cycles of treatment in group A were $12.8 \%$ and $8.8 \%$ respectively. While in group B pregnancy and live birth rates were $11.9 \%$ and $7.5 \%$ respectively.

These results were in accordance with Kamath et al. [16], who studied the effect of letrozole versus placebo in CCR-PCOS patients, letrozole was better than placebo for ovulation rate per patient $(6$ of $18,33.33 \%$ versus none of $18,0 \%, p=$ 0.006). However, no difference in pregnancy rate per patient (1 of $18,5.55 \%$ versus none of $18,0 \%, p=0.324$ ) or live birth rate per patient ( 1 of $18,5.55 \%$ versus none of $18,0 \%, \mathrm{p}=0.324$ ) [16].

In addition, Chen and Zhang in 2016 compared the effect of CC + HMG, Letrozole + HMG and Letrozole + CC in patients with CCR-PCOS and found that combination of Letrozole + CC could achieve $30.77 \%$ ovulation rate. But when both are combined with HMG, the ovulation rate was significantly higher than LE + HMG and CC + HMG, with lower risk of multiple pregnancy and OHSS [17].

Elnashar et al., studied the effect of letrozole on 44 patients with CCR-PCOS, and found that ovulation occurred $54.6 \%$ of patients, pregnancy occurred in $25 \%$ of patients and the mean endometrial thickness was $10.2 \mathrm{~mm}$ [18].

Rezk et al., compare the effect of letrozole alone versus combination of clomiphene citrate and metformin in CCR-PCOS patients and found higher ovulation and clinical pregnancy rate with letrozole alone with unexpectedly higher multiple pregnancy rate [19].

Justice et al., in 2013 studied the effect of simultaneous clomiphene citrate and letrozole therapy for ovulation induction in CCR-PCOS and concluded that it can be considered for ovulation induction in patients who are resistant to single-agent therapy prior to proceeding to gonadotropins therapy [20]. Also, Mejia et al. [13] found a higher ovulation rate with simultaneous clomiphene citrate and letrozole therapy when compared with of letrozole alone (77\% vs. $43 \%)$.

However, we found that simultaneous use of letrozole and CC did not add any benefit over letrozole alone in CCR-PCOS patients in terms of ovulation rate, follicular volume, pregnancy rate and live birth rate.

This study has some limitations, after randomization the investigator and patient were not blinded to the treatment therefore subjected to biases. However, Measurement of serum Progesterone levels 7 days after the expected time of ovulation would minimize any bias occured from a lack of blinding.

The present study offered a cost-effective and reasonable tool to obtain ovulatory data on managing CCR-PCOS patients. 


\section{Conclusion}

Letrozole alone or simultaneous use of letrozole and CC offers a good secondline option for ovulation induction in patients with CCR-PCOS. However, the combination of CC and letrozole did not add any benefit over the use of letrozole alone regards ovulation rate, follicular volume, endometrial thickness, pregnancy rate and live birth rate.

\section{Acknowledgements}

The author thanks all patients who participated in the study. There is no financial support and conflicts of interest in this study.

\section{Conflicts of Interest}

The author declares no conflicts of interest regarding the publication of this paper.

\section{References}

[1] Priya, M.R., Nanthini, A. and Bini, K.P. (2019) Polycystic Ovary Syndrome: An Updated Review. International Journal of Health \& Allied Sciences, 8, 229-235. https://doi.org/10.4103/ijhas.IJHAS_9_19

[2] Wang, R. and Mol, B.W. (2017) The Rotterdam Criteria for Polycystic Ovary Syndrome: Evidence-Based Criteria? Human Reproduction, 32, 261-264. https://doi.org/10.1093/humrep/dew287

[3] Garg, N. and Vanitha, V.G. (2019) A Comparative Study of Letrozole vs Clomiphene Citrate as First Line for Anovulatory Infertility-An Institutional Experience. Asian Research Journal of Gynaecology and Obstetrics, 2, 1-8.

[4] Takasaki, A., Tamura, I., Okada-Hayashi, M., et al. (2018) Usefulness of Intermittent Clomiphene Citrate Treatment for Women with Polycystic Ovarian Syndrome That Is Resistant to Standard Clomiphene Citrate Treatment. Reproductive Medicine and Biology, 17, 454-458. https://doi.org/10.1002/rmb2.12219

[5] SalaheldinAbdelHamid, A.M., Rateb, A.M. and Ismail Madkour, W.A. (2016) Is Clomiphene Citrate Stair-Step Protocol a Good Alternative to Gonadotrophins in Clomiphene-Resistant PCO Patients? Prospective Study. Journal of Obstetrics and Gynaecology Research, 42, 547-553. https://doi.org/10.1111/jog.12940

[6] Sachdeva, G., Gainder, S., Suri, V., Sachdeva, N. and Chopra, S. (2019) Comparison of Clinical, Metabolic, Hormonal, and Ultrasound Parameters among the Clomiphene Citrate-Resistant and Clomiphene Citrate-Sensitive Polycystic Ovary Syndrome Women. Journal of Human Reproductive Sciences, 12, 216-223. https://doi.org/10.4103/jhrs.JHRS_89_18

[7] Mohammed, N.S., Salah, R.A., Ahmed, M.A., Ahmed, N.S., Abd El-Rahman, M.S., et al. (2017) Short Term Effects of Laparoscopic Ovarian Drilling in Clomiphene Citrate Resistant Patients with Polycystic Ovary Syndrome. Middle East Fertility Society Journal, 22, 290-294. https://doi.org/10.1016/j.mefs.2017.04.008

[8] Vause, T.D., Cheung, A.P., Sierra, S., et al. (2010) Ovulationinduction in Polycystic Ovary Syndrome. Journal of Obstetrics and Gynaecology Canada, 32, 495-502. https://doi.org/10.1016/S1701-2163(16)34504-2

[9] Felemban, A., Lin, T.S. and Tulandi, T. (2000) Laparoscopic Treatment of Polycystic 
Ovaries with Insulated Needle Cautery: A Reappraisal. Fertility and Sterility, 73, 266-269. https://doi.org/10.1016/S0015-0282(99)00534-8

[10] Haynesa, B.P., Dowsetta, M., Millerb, W.R., et al. (2003) The Pharmacology of Letrozole a Mini Review. Journal of Steroid Biochemistry \& Molecular Biology, 87, 35-45. https://doi.org/10.1016/S0960-0760(03)00384-4

[11] Teede, H.J., Misso, M.L., Costello, M.F., et al. (2018) International PCOS Network Recommendation from the International Evidence Based Guideline for the Assessment and Management of Polycystic Ovary Syndrome. Fertility and Sterility, 110, 364-379. https://doi.org/10.1016/j.fertnstert.2018.05.004

[12] Bayar, U., Basaran, M., Kiran, S., et al. (2006) Use of an Aromatase Inhibitor in Patients with Polycystic Ovary Syndrome: A Prospective Randomized Trial. Fertility and Sterility, 86, 1447-1451. https://doi.org/10.1016/j.fertnstert.2006.04.026

[13] Mejia, R.B., Summers, K.M., Kresowik, J.D., et al. (2019) A Randomized Controlled Trial of Combination Letrozole and Clomiphene Citrate or Letrozole Alone for Ovulation Induction in Women with Polycystic Ovary Syndrome. Fertility \& Sterility, 111, 571-578. https://doi.org/10.1016/j.fertnstert.2018.11.030

[14] Hajishafiha, M., Dehghan, M., Kiarang, N., et al. (2013) Combined Letrozole and Clomiphene versus Letrozole and Clomiphene Alone in Infertile Patients with Polycystic Ovary Syndrome. Drug Design, Development and Therapy, 7, 1427-1431. https://doi.org/10.2147/DDDT.S50972

[15] The Rotterdam ESHRE/ASRM-Sponsored PCOS Consensus Workshop Group (2004) Revised 2003 Consensus on Diagnostic Criteria and Long Term Health Risks Related to PCOS. Human Reproduction, 19, 41-47. https://doi.org/10.1093/humrep/deh098

[16] Kamath, M.S., Aleyamma, T.K., Chandy, A., et al. (2010) Aromatase Inhibitors in Women with Clomiphene Citrate Resistant: A Randomized, Double-Blind, Placebo-Controlled Trial. Fertility \& Sterility, 94, 2857-2859. https://doi.org/10.1016/j.fertnstert.2010.06.008

[17] Chen, Y. and Zhang, D. (2016) Optimal Ovulation Induction in Polycystic Ovary Syndrome Resistant to Clomiphene Citrate or Letrozole. Journal of Sichuan University, 47, 874-877.

[18] Elnashar, A., Fouad, H., Eldosoky, M., et al. (2004) Letrozole Induction of Ovulation in Clomiphene Citrate Resistant Polycystic Ovary Syndrome: Responders and Non-Responders. Middle East Fertility Society Journal, 9, 157-162.

[19] Rezk, M., Shaheen, A.E. and Saif El-Nasr, I. (2018) Clomiphene Citrate Combined with Metformin versus Letrozole for Induction of Ovulation in Clomiphene-Resistant Polycystic Ovary Syndrome: A Randomized Clinical Trial. Gynecological Endocrinology, 34, 298-300. https://doi.org/10.1080/09513590.2017.1395838

[20] Justice, T.D., Nakajima, S.T. and Bohler, H.C.L. (2013) Simultaneous Clomiphene Citrate and Letrozole Therapy for Ovulation Induction in Clomiphene-Resistant Polycystic Ovarian Syndrome. Fertility \& Sterility, 99, S36. https://doi.org/10.1016/j.fertnstert.2013.01.082 